\title{
Radiotherapy as a tool for the treatment of Cushing's disease
}

\author{
Frederic Castinetti ${ }^{1,2}$, Thierry Brue ${ }^{1,2}$ and Oskar Ragnarsson ${ }^{3,4}$ \\ ${ }^{1}$ Aix-Marseille Université, Institut National de la Santé et de la Recherche Médicale, Marseille Medical Genetics, \\ Marseille, France, ${ }^{2}$ Department of Endocrinology, Assistance Publique-Hôpitaux de Marseille, Hôpital de la \\ Conception, Centre de Référence des Maladies Rares de I'hypophyse, Marseille, France, ${ }^{3}$ Department of Internal \\ Medicine and Clinical Nutrition, Institute of Medicine at Sahlgrenska Academy, University of Gothenburg, \\ Gothenburg, Sweden, and ${ }^{4}$ Department of Endocrinology, Sahlgrenska University Hospital, Göteborg, Sweden
}

\author{
Correspondence \\ should be addressed \\ to $\mathrm{F}$ Castinetti or $\mathrm{O}$ \\ Ragnarsson \\ Email \\ frederic.castinetti@ap-hm.fr \\ or oskar.ragnarsson@medic. \\ gu.se
}

\begin{abstract}
Treatment of Cushing's disease (CD) is one of the most challenging tasks in endocrinology. The first-line treatment, transsphenoidal pituitary surgery, is associated with a high failure rate and a high prevalence of recurrence.

Re-operation is associated with an even higher rate of a failure and recurrence. There are three main second-line treatments for CD - pituitary radiation therapy (RT), bilateral adrenalectomy and chronic cortisol-lowering medical treatment. All these treatments have their limitations. While bilateral adrenalectomy provides permanent cure of the hypercortisolism in all patients, the unavoidable chronic adrenal insufficiency and the risk of development of Nelson syndrome are of concern. Chronic cortisol-lowering medical treatment is not efficient in all patients and side effects are often a limiting factor. RT is efficient for approximately two-thirds of all patients with CD. However, the high prevalence of pituitary insufficiency is of concern as well as potential optic nerve damage, development of cerebrovascular disease and secondary brain tumours. Thus, when it comes to decide appropriate treatment for patients with $C D$, who have either failed to achieve remission with pituitary surgery, or patients with recurrence, the pros and cons of all second-line treatment options must be considered.
\end{abstract}

\section{Introduction}

The first-line treatment of Cushing's disease (CD) is transsphenoidal surgery (1). Surgery is, however, not always effective. Roughly $50 \%$ of the patients achieve immediate remission, and a high rate of recurrence (20-30\%) during the first 5 years following the procedure has been reported $(2,3)$. Despite a multimodal therapeutic approach in patients who fail to achieve remission with surgery, control of hypercortisolism can be difficult, even at expert centres (4). In a large multicentre study, including 230 patients, Geer and colleagues recently reported that only half of patients with CD were under biochemical control after a median follow-up of 1.9 years (4). Important to notice is, however, that the study included patients treated at a tertiary referral centres, that is, patient probably often with a more complicated disease. The efficacy rate in general might therefore be higher. 
patients who have failed transsphenoidal surgery or have recurrent CD (1). However, they also suggest that patients with $\mathrm{CD}$ who have underwent a non-curative surgery, or for whom surgery was not possible, a shared decisionmaking approach should be used since several second-line therapies are available, including repeat transsphenoidal surgery, RT, chronic cortisol-lowering medical treatment and bilateral adrenalectomy.

Pituitary RT is a general term that includes several different radiation techniques. Radiation can be delivered stereotactically or not, on a single occasion or during multiple sessions. During conventional RT (CRT), small radiation doses are given on a number of occasions, typically $2 \mathrm{~Gy}$, five times per week until a cumulative dose of 45-50 Gy has been reached. Recently, several technical improvements have evolved in CRT, such as the intensitymodulated radiotherapy, image-guided radiotherapy and volumetric modulated arc therapy (8). These techniques allow a more precise dose adjustment, with the aim of sparing the structures surrounding the target lesion.

Stereotactic RT can be given on a single occasion or fractionated on several occasions. During stereotactic radiosurgery (SRS), the whole radiation dose is given on a single occasion, typically $20 \mathrm{~Gy}$, making it more convenient for the patient compared to CRT. The most common SRS methods used today are the gamma Knife and a linear accelerator. SRS should be reserved for smaller lesions, where the dose to the optic chiasm should not exceed 8Gy, and the distance from the target and the optic chiasm should be at least $3-5 \mathrm{~mm}$ (9). Fractionated stereotactic radiotherapy, that is lower radiation doses given on multiple sessions with stereotaxy, can be used for larger lesions. Indeed, higher number of sessions decreases the toxicity for adjacent structures. Cyberknife uses a low number of sessions for fractionation. Finally, proton beam radiation can also be used with the theoretical benefit of the lack of diffusion of the radiation, and thus a decreased risk of side effects.

In this paper we discuss the pros and cons concerning $\mathrm{RT}$ in patients with CD.

\section{Pro}

\section{Radiation techniques have a good rate of antisecretory efficacy, and they can cure the patient}

Data on antisecretory efficacy of radiation techniques are mainly based on CRT studies, that is studies reported for more than 10 years ago. These series have the main advantage of their very long-term follow-up for the assessment of outcome. With this technique, high efficacy (cure rate exceeding 80\%) was always associated with poor tolerance (more than $50 \%$ of the patients had pituitary deficits), especially in terms of new onset of pituitary deficits (10).

CRT is less frequently used, and its updated version, conformal radiotherapy, did not show yet its long-term efficacy for pituitary adenomas in the literature. For instance, Jensen et al. reported the efficacy of intensitymodulated radiotherapy in two patients with CD (11). Further long-term studies are thus needed to precisely determine the benefits of the modern modalities of radiotherapy.

However, other modern techniques have shown to be effective in CD. For instance, we and others have reported a long-term antisecretory efficacy of SRS in $35-83 \%$ cases over the last 15 years (12). The largest series reporting the efficacy of gamma Knife radiosurgery in CD was recently published (13). A total of 278 patients were followed for a mean period of 5.6 years: control of hypercortisolism was $80 \%$ at 10 years, while recurrences were observed in $18 \%$ cases after a mean duration of 38 months. This latter result is of importance, as recurrence was initially considered unlikely in patients treated with CRT. In a recent meta-analysis, Abu Dabrh et al. reported a 32\% rate of recurrence in patients treated by radiosurgery (14). Interestingly, Mehta et al. also reported that the mean time to reach the maximal antisecretory efficacy was 14.5 months, which means that medical treatments aimed at controlling hypercortisolism while waiting for the effect of RT, would only be given for a rather short period of time (13). This is of importance, as it is generally thought that control of hypersecretion can only be observed after a very prolonged period of time (as was evidenced with CRT). Of note, Sheehan et al. recently showed that the remission appeared earlier in CD than in acromegaly (15).

Whether treatment with somatostatin analogues reduces the efficacy of SRS with gamma Knife in patients with pituitary adenoma has been raised regularly for several years and remains a matter of debate. It was indeed suggested that somatostatin analogues compromise the efficacy of the gamma Knife by decreasing cell proliferation in pituitary adenomas. This is, however, still controversial. Roughly half of the studies that have addressed this topic have considered somatostatin analogues at the time of radiosurgery to be a negative predictive factor for remission, while the other half have not shown any difference between treated and untreated patients (16). Even though a firm scientific support is lacking, in patients with $\mathrm{CD}$ receiving treatment with pasireotide, we suggest withdrawal for at least 3 months 
before gamma Knife treatment is initiated. A potential negative effect of treatment with ketoconazole at the time of gamma Knife on efficacy has also been reported (12). Only 3 of 15 patients receiving ketoconazole achieved remission compared to 12 of 25 patients without. A direct effect of ketoconazole on the pituitary has been suggested (17). Although this central effect seems speculative, we also suggest that ketoconazole should be stopped 2-4 weeks before RT.

Results of antisecretory efficacy were comparable in a small series of patients treated by Cyberknife (18). All these studies were dealing with a majority of patients treated with a visible remnant after surgery $(88 \%$ of the patients by Mehta et al., for instance) (13). This is however not always the case in $\mathrm{CD}$, especially in patients with post-surgical remission, and presenting with delayed recurrence. Shepard et al. recently reported an international experience of gamma Knife in patients without an obvious remnant: they delivered whole-sellar SRS in 68 patients with CD (19). The 5-year actuarial remission rate was $75.9 \%$, and the recurrence rate was $14 \%$. Results were thus comparable with those obtained in patients treated for a visible remnant (19).

As a summary, literature data confirm the good antisecretory efficacy of modern radiation techniques. Roughly $60 \%$ of the patients will be cured on a long-term basis, while 15-20\% will recur after an initial period of remission. In comparison with other treatments, RT can thus be considered an effective antisecretory option, allowing definite cure in a high number of patients.

Of note, the majority of the patients reported in these studies were treated with CRT or SRS after failed transsphenoidal surgery. Only few data are available in the literature on the use of radiosurgery as a first-line treatment for CD. In the study by Castinetti et al., 27 patients, including six with $\mathrm{CD}$, were treated with gamma Knife as a first-line treatment. The main indication was visible pituitary adenoma localised in, or invading, the cavernous sinus, that is patients for whom surgery would not been curative. Rate of remission was 50\% after a follow-up for a minimum of 5 years (20). Mehta et al. reported that 23 of 327 patients (8\%) followed for CD were treated by gamma Knife as a first-line treatment and that 15 of these experienced durable control of hypercortisolism (13). The specific reasons for gamma Knife as a first-line treatment was not mentioned. Some of these patients may however also be included in the follow-up study from the same group where six patients, apparently without a visible adenoma on MRI, were treated with gamma Knife (19). Results on efficacy, specific for these patients were, however, not provided. Although the efficacy of RT as a first- or second-line treatment seem to be similar, the low number of patients studied so far make it difficult to draw any firm conclusion. However, SRS with gamma Knife seems to be a good treatment option in patients who are not candidates for surgery, especially patients with an adenoma invading the cavernous sinus.

\section{Different modalities of radiation techniques allow for a better targeting of the remnant and spare the surrounding structures}

The term 'RT' does not mean anything precise enough. Indeed, as previously mentioned, there are now several modalities of radiation techniques which could be used depending on the characteristics of the tumour. It is something to always keep in mind when trying to determine the benefits of radiation techniques. The majority of the studies with a prolonged follow-up are based on older techniques of the so-called CRT, sometimes used with a guiding imaging procedure based on brain imaging. The accuracy of the newer techniques, combined with the accuracy of current imaging procedures, will undoubtedly lead to a much lower risk of side effects.

For instance, the rate of gamma Knife-induced hypopituitarism varies between 14 and 62\% (20) and can be observed 12-96 months after the procedure, requiring a prolonged follow-up. These rates of hypopituitarism are the ones usually reported when treating secreting pituitary adenomas (21), as evidenced by Lee in acromegaly (22) or in the treatment of non-functioning pituitary adenomas $(23,24)$. These rates are also close to the ones reported for fractionated SRS (25).

In $\mathrm{CD}$, the majority of the patients with failed surgery will either present a small remnant in the cavernous sinus or a lack of a visible remnant. In the latter case, the choice of radiation technique is a matter of debate as it would lead to a totosellar irradiation, and it would be considered that this could lead to a massive rate of hypopituitarism. However, Shepard et al. did not report a significantly higher risk of pituitary deficiencies, compared to targeted radiosurgery, that is new pituitary deficiency occurred in $23 \%$ of the patients (19), a rate that is close to the one observed when the radiosurgery was performed with a visualised target on magnetic resonance imaging.

While CRT has been suggested to be associated with extra-pituitary side effects, with seemingly an increased risk of stroke, cognitive decline and secondary tumours $(26,27,28,29,30)$, these risks have never been clearly demonstrated with the most recent techniques. This could 
be due to a better tolerance profile or to an insufficient follow-up. In a preliminary study based on 14 patients treated by gamma Knife for a pituitary adenoma, Tooze et al. did not shown any cognitive decline after a median follow-up of 26 months (31).

As a summary, the tolerance profile of the new modalities of radiation techniques seems to be clearly improved compared to the observations in patients treated with CRT. However, the majority of studies based on the most recent techniques are biased by a much shorter follow-up than the one used for CRT. Prolonged follow-up will likely confirm these safety data.

\section{The other treatments aimed at controlling hypersecretion have their own limits}

When surgery fails, the modalities of treatment are not consensual. They can either be based on long-term cortisol-lowering medications such as ketoconazole, metyrapone or pasireotide or on bilateral adrenalectomy (not mentioning radiation techniques) $(32,33,34)$. Each approach has its own caveats. For instance, while medical treatment is usually effective in roughly $50 \%$ cases (some of these results being only based on retrospective studies), it does not allow for cure of the disease (35). Recurrence of hypercortisolism is indeed observed shortly after drug withdrawal and the tolerance is not always perfect, with risks of liver enzyme increment, worsening hypokalaemia, hypertension and diabetes. Moreover, defining eucortisolism on treatment is a tough task. While some authors consider that eucortisolism is obtained when 24-h urinary free cortisol is normal, others suggest that the aim of medical treatment is to restore the circadian rhythm. Mild hyper- or hypocortisolism can lead to longterm comorbidities.

Bilateral adrenalectomy has the main advantage of curing the patient from its disease, but it replaces Cushing's syndrome with adrenal insufficiency. Adrenal insufficiency requires lifelong treatment with glucocorticoids and induces an increased morbidity and mortality and reduced quality of life (36). Risks of Nelson's syndrome, that is the risk of growth of a corticotroph tumour after bilateral adrenalectomy, is estimated to be around $20 \%(37,38)$.

\section{Pro - Summary}

When trying to determine the roles of radiation techniques in the management of $\mathrm{CD}$, one should always keep in mind the limitations of other treatments aimed at controlling hypercortisolism. As the majority of the patients will be in their 40-50s at the time of diagnosis, any treatment not aimed at curing the patient will thus have to be maintained on a very long-term basis, that is for $30-40$ years. As we still lack the optimal treatment that makes it sure that eucortisolism is obtained, and maintained, radical curative treatments should always be considered, even though they lead to adrenal insufficiency, another challenging disease to treat. Thus, we consider that radiotherapy still has a major role to play in the management of CD. Even with new drugs, the rationale will always be a balance between curative treatment and long-term medical treatment aimed at 'only' controlling the disease. While new pituitarydirected drugs may become available in the next few years, it is also likely that new techniques, especially in terms of target definition, will develop for radiation techniques, resulting in increased efficacy and improved tolerance. Given the difficulties in treating patients with $\mathrm{CD}$, it is likely that RT and radiosurgery will still have a role to play in the future.

\section{Con}

\section{Efficacy}

Mortality is increased in patients with CD, especially in patients who are not in remission $(39,40,41,42,43,44,45)$. The incidence of serious comorbidities such as acute myocardial infarction, venous thromboembolism, stroke and severe infections are also increased $(44,46,47)$. Efficient treatment is therefore of fundamental importance in the management of patients with CD.

Approximately $15 \%$ of patients with CD due to a microadenoma, who are treated with transsphenoidal pituitary surgery, do not achieve remission (9). Furthermore, at least $10 \%$ of patients who initially are in remission experience recurrence (9). The remission rate following a second pituitary surgery for persistent or recurrent disease is even lower $(9,48)$. All patients treated with bilateral adrenalectomy achieve immediate remission.

Although CRT offers an good tumour control, obtained in $93-100 \%$ of all patients with CD $(49,50,51$, $52,53)$, the remission rate varies between 46 and $84 \%$ in several large series $(49,50,51,52,53,54)$. In one of these, the median time to remission was 24 months, with a remission rate at $1,3,5$ and 10 years of $8,73,74$ and $83 \%$, respectively (50). Furthermore, a high recurrence rate (25-50\%) following CRT has been reported in some studies $(51,54,55)$, but lower in other $(49,50,53)$. 
The efficacy of treatment with SRS in patients with CD seems to be comparable to CRT. In studies including more than 30 patients, the remission rate varies between 52 and $70 \%$, and the mean and median time to remission varies between 7 and 22 and 16 and 17 months, respectively (12, $56,57,58,59)$. In three studies the disease recurred in $20-24 \%$ of patients who initially had achieved remission $(56,58,59)$, but in none in two other studies $(12,57)$. In a recent international multicentre retrospective study, the largest study published to date, on 278 patients with CD who had been treated with a single session SRS (92\% following unsuccessful pituitary surgery and $8 \%$ as primary treatment), 193 patients (69\%) achieved biochemical remission after a median time of 12 months (13). After this initial remission, the disease recurred in 35 patients (18\%). Thus, at the last follow-up, 43\% of the cohort had an uncontrolled hypercortisolism. In the same cohort, when comparing patients who had received whole-sellar $(n=68)$ and discreet adenoma targeted SRS $(n=210)$, no difference was seen in remission rate, time to remission or recurrence rate (19).

SRS using proton beams has recently been studied in 74 patients with CD (60). Complete remission was achieved in 54 and 67\%, after 3 and 5 years of follow-up, respectively. The median time to remission was 32 months and only one patient had a recurrence.

Thus, far from all patients with CD achieve remission after RT, and for those who do, this takes a long time and carries a considerable risk of recurrence. Also, pending the effect if RT, patients with CD often need cortisollowering pharmacological treatment for years, that is treatment with its own limitations concerning efficacy and tolerability.

\section{Hypopituitarism}

Hypopituitarism is associated with increased morbidity and mortality $(61,62)$. The development of pituitary insufficiency is therefore another major concern in patients with CD who are treated with pituitary RT.

In a study on 40 patients who received CRT after unsuccessful pituitary surgery, the prevalence of hypopituitarism increased from 25 to $62 \%$, 5 years following RT, and to $76 \%$ after 10 years of follow-up (50). After a median follow-up time of 9 years, $70 \%$ had hypogonadotropic hypogonadism, 65\% had central hypothyroidism, 43\% had growth hormone deficiency and among patients in biochemical remission, 56\% were receiving glucocorticoid replacement. In other studies, often with a shorter follow-up time, the prevalence of hypopituitarism following CRT varies between 23 and $67 \%(49,51,53,54)$.

The prevalence of hypopituitarism following SRS seems to be somewhat lower than after CRT, ranging between 15 and $36 \%(12,56,57,58,59)$. In the previously mentioned multicentre study by Mehta et al., with a mean follow-up of 5.6 years, $25 \%$ of the cohort developed new hormone deficiencies following SRS; $17 \%$ developed central hypothyroidism and 10\% developed growth hormone deficiency and 10\% hypogonadotropic hypogonadism (13). Since the prevalence of pituitary hormone deficiencies increases with time, a short follow-up time in several of these studies may be the reason for the assumption that SRS is associated with lower risk of hypopituitarism compared to CRT. Furthermore, information on how pituitary function was evaluated, especially growth hormone and sex hormones, is frequently lacking, making it possible that hypopituitarism is underdiagnosed in many of the studies published to date. Following proton beam RT for patients with functioning pituitary adenoma, including 74 patients with CD, 45 and $62 \%$ of the patients had at least one new pituitary deficiency after 3 and 5 years, respectively (60).

Thus, hypopituitarism is a significant and serious problem following treatment with CRT and SRS. A substantial number of patients develop secondary adrenal insufficiency following RT. Glucocorticoid replacement therapy and/or secondary adrenal insufficiency per se is associated with high BMI, increased waist circumference and adverse lipid profile (63), reduced bone mineral density (64) and impaired quality of life $(65,66)$. Last but not least, secondary adrenal insufficiency $(45,67,68)$, as well as untreated gonadotropin-deficiency $(67,69)$, are associated with increased mortality. Also, central hypothyroidism (70) and growth hormone deficiency (71) are associated with adverse cardiometabolic profiles. Furthermore, at least half of all patients diagnosed with CD are young adults (72). Fertility is therefore another important issue for a large number of patients with CD.

\section{Cranial nerves}

Optic nerve damage after CRT seems to be low (reviewed in (9)). In a large study on 217 patients treated with SRS for secretory and non-secretory pituitary adenoma, 9 (4\%) developed new or worsening visual dysfunctions, of whom three had permanent deficits (two visual field defects, one ophthalmoplegia) (73). In a study by Jagannathan et al., 5 of 90 patients (5.5\%) with CD developed ophthalmoplegia after SRS, 4 of whom had 
also a new decrease in visual acuity (58). In addition, one patient, treated three times with RT, developed visual field defects that progressed to blindness in both eyes. In another large study including 278 patients with CD, new cranial neuropathy, unrelated to tumour progression, was experienced in seven patients (3\%); four had visual field defects and four had ophthalmoplegia (one patient had both visual field defects and ophthalmoplegia) (13). Two additional, fairly large studies $(n=40$ and 90$)$ have reported optic nerve damage in $5 \%$ of patients with $\mathrm{CD}$ treated with SRS $(12,59)$.

Although cranial nerve damage can be considered a relatively uncommon complication following RT, especially CRT, it is certainly a serious complication that can have devastating effect on the individual patient.

\section{Effects of radiation on the central nervous system}

It has been suggested that patients treated with RT due to pituitary adenoma have an increased risk of developing a second intracranial tumour $(27,28,74)$. In a recent paper by Yamanaka et al., all cases of second intracranial tumour published between 1959 and 2017 were systematically reviewed; 46 gliomas (9, grade II; 14, grade III; and 22, grade IV), 37 meningiomas, 52 sarcomas, one primitive neuroepithelial tumour and one neuroblastoma (75). The mean time from RT to the diagnosis of a second intracranial tumour was 15 years; 13 years for gliomas and 20 years for meningiomas. In a study from Sweden, 6 out of 298 patients with pituitary adenoma, treated with CRT, developed a second intracranial tumour (four meningiomas and two gliomas), compared to the expected number of 1.2 in the general population (SIR 5.2 (95\% CI 1.9-11)) (76). In a study from the United Kingdom, 5 out of 334 patients treated with pituitary RT were diagnosed with a second brain tumour, resulting in a SIR of 9.4 (95\% CI 3.1-22) (77). In the same cohort, followed-up for additional 10 years, 11 patients had developed a second brain tumour (five meningiomas, four high-grade astrocytomas, one meningeal sarcoma and one primitive neuroectodermal tumour) (78). Thus, the cumulative risk, 20 years after RT, was $2.4 \%$. However, in a large Dutch study, the incidence of second intracranial tumours in 236 patients treated with postoperative RT did not differ from the incidence in 226 patients treated with surgery alone (79). The median follow-up time in irradiated patients was 14 years. The most comprehensive study published to date included 8917 patients with hypopituitarism of various aetiologies, of whom 3236 had received RT (28). Forty-four second intracranial tumours were identified, 22 meningiomas and 17 malignant brain tumours. The relative risk for patients who had received RT, compared to non-irradiated patients, was increased, both for meningiomas (4.06 (95\% CI, 1.51-10.9)) as well as malignant brain tumours (3.34 (95\% CI 1.06-10.6)) . Highest risk was seen in patients who had received RT before the age of 30 years and the incidence rate of second intracranial tumour was similar in patients treated with CRT and SRS (28).

In a study on 331 patients with various types of pituitary adenomas, 64 developed cerebrovascular disease following postoperative RT (relative risk 4.1 (95\% CI 3.6-4.7)) (80). However, since all the patients had also been operated, a causative relationship between cerebrovascular events and RT could not be confirmed. Also, having a pituitary adenoma, per se, is associated with increased risk of cerebrovascular disease (81). Two large studies on patients with pituitary adenoma have analysed the incidence of cerebrovascular events in patients who had received RT and compared it to the incidence in nonirradiated patients $(30,82)$. In a study on 806 patients with non-functioning pituitary adenoma, van Varssevald et al. found an increased incidence of cerebrovascular events in men who had received RT (hazard ratio 3.0 (95\% CI 1.3-6.8)), but not in women (82). Sattler et al. demonstrated a higher incidence of stroke in a cohort of 462 patients compared to the general population, but no difference between patients treated with RT and patients treated with surgery alone (30). Only five studies have analysed the possible association between SRS and cerebrovascular events (reviewed in (83)). All are limited by a small number of patients $(n=27-53)$ and therefore provides unreliable results. Patients with active CS have an increased risk of stroke. In a large study, including 343 patients with CS from Denmark, the risk for stroke, preand peri-operatively, was more than fourfold compared to controls from the background population (47). Similarly, in large cohort from Sweden $(n=502)$, mortality due to cerebral infarction in patients with $\mathrm{CD}$ was three times higher than in the background population (45). Thus, the greatly increased risk of cerebrovascular disease in patients with $\mathrm{CD}$ should be taken into account before treatment with RT, possibly also associated with increased incidence of cerebrovascular complications, is considered.

The possibility of cognitive deterioration following RT is also of concern. In two studies, executive function was worse following RT in patients with pituitary adenoma compared to non-radiated patients $(84,85)$. Impaired verbal memory has also be associated with RT in two studies $(85,86)$. On the contrary, there are also studies 
that have not been able to demonstrate difference in cognitive function between irradiated and non-irradiated patients with pituitary adenoma $(31,87)$. However, it is important to acknowledge that the number of patients in these studies is small and the follow-up time is relatively short. For instance, in the most recent study showing no association between RT on cognitive function, only 21 irradiated patients were included, and the mean time from treatment was 4 years (88). To be able to capture cognitive deficits with standardised neuropsychological tests, larger cohorts and longer follow-up time is needed.

\section{Con - Summary}

The limited efficacy, as well as a high prevalence of recurrence and hypopituitarism, are the two main reasons to be concerned for patients with CD treated with pituitary RT. A substantial number of patients treated with RT does not achieve remission, and for those who do, this takes a long time. Furthermore, recurrence is common and more than half of all patients treated with RT develop hypopituitarism. Although not common, development of secondary brain tumours, cerebrovascular disease and adverse effects on vision can have a devastating effects on the individual patient.

\section{Conclusions}

Treatment of CD is one of the most challenging tasks in endocrinology. The first-line treatment, transsphenoidal pituitary surgery, is associated with a high failure rate and a high prevalence of recurrence. Re-operation is associated with an even higher rate of a failure and recurrence. There are three main second-line treatments for CD - pituitary RT, bilateral adrenalectomy and chronic cortisol-lowering medical treatment. All these treatments have their limitations. While bilateral adrenalectomy provides permanent cure of the hypercortisolism in all patients, the unavoidable chronic adrenal insufficiency and the risk of development of Nelson's syndrome are of concern. Chronic cortisol-lowering medical treatment is not efficient in all patients and side effects are often a limiting factor. RT is efficient for approximately two-thirds of all patients with CD. However, the high prevalence of pituitary insufficiency is of concern, as well as a potential optic nerve damage, development of cerebrovascular disease and secondary brain tumours. Thus, when it comes to decide appropriate treatment for patients with CD who have either failed to achieve remission with pituitary surgery, or patients with recurrence, the pros and cons of all second-line treatment options must be considered.

\section{Declaration of interest}

O R has received lecture fees from Novo Nordisk, Ipsen, Sandoz and Pfizer, an unrestricted research grant from HRA-pharma and consultancy fees from Novartis and HRA-pharma. F C and T B have received lecture fees, consultancy fees and unrestricted research grants from Novartis, Ipsen and Pfizer and HRA-pharma.

\section{Funding}

This research did not receive any specific grant from any funding agency in the public, commercial or not-for-profit sector.

\section{Author contribution statement}

Frederic Castinetti and Thierry Brue wrote the pro section of the paper and Oskar Ragnarsson the con section. All authors wrote the introduction and conclusion sections.

\section{References}

1 Nieman LK, Biller BM, Findling JW, Murad MH, Newell-Price J, Savage MO, Tabarin A \& Endocrine Society. Treatment of Cushing's syndrome: an Endocrine Society clinical practice guideline. Journal of Clinical Endocrinology and Metabolism 2015100 2807-2831. (https:// doi.org/10.1210/jc.2015-1818)

2 Aranda G, Ensenat J, Mora M, Puig-Domingo M, Martinez de Osaba MJ, Casals G, Verger E, Ribalta MT, Hanzu FA \& Halperin I. Long-term remission and recurrence rate in a cohort of Cushing's disease: the need for long-term follow-up. Pituitary 201518 142-149. (https://doi.org/10.1007/s11102-014-0567-8)

3 Patil CG, Prevedello DM, Lad SP, Vance ML, Thorner MO, Katznelson L \& Laws ER Jr. Late recurrences of Cushing's disease after initial successful transsphenoidal surgery. Journal of Clinical Endocrinology and Metabolism 200893 358-362. (https://doi. org/10.1210/jc.2007-2013)

4 Geer EB, Shafiq I, Gordon MB, Bonert V, Ayala A, Swerdloff RS, Katznelson L, Lalazar Y, Manuylova E, Pulaski-Liebert KJ et al. Biochemical control during long-term follow-up of 230 adult patients with Cushing disease: a multicenter retrospective study. Endocrine Practice 201723 962-970. (https://doi.org/10.4158/ EP171787.OR)

5 Castinetti F \& Brue T. Pituitary gland: gamma Knife for Cushing disease - time for a reappraisal? Nature Reviews: Endocrinology 201713 628-629. (https://doi.org/10.1038/nrendo.2017.130)

6 Cushing H. The basophil adenomas of the pituitary body and their clinical manifestations (pituitary basophilism). Johns Hopkins Hospital Bulletin 193250 137-195.

7 Lacroix A, Feelders RA, Stratakis CA \& Nieman LK. Cushing's syndrome. Lancet 2015386 913-927. (https://doi.org/10.1016/ S0140-6736(14)61375-1)

8 Minniti G, Gilbert DC \& Brada M. Modern techniques for pituitary radiotherapy. Reviews in Endocrine and Metabolic Disorders 200910 135-144. (https://doi.org/10.1007/s11154-008-9106-0)

9 Pivonello R, De Leo M, Cozzolino A \& Colao A. The treatment of Cushing's disease. Endocrine Reviews 201536 385-486. (https://doi. org/10.1210/er.2013-1048)

10 Jenkins PJ, Bates P, Carson MN, Stewart PM \& Wass JA. Conventional pituitary irradiation is effective in lowering serum growth hormone 
and insulin-like growth factor-I in patients with acromegaly. Journal of Clinical Endocrinology and Metabolism 200691 1239-1245. (https:// doi.org/10.1210/jc.2005-1616)

11 Jensen RL, Jensen PR, Shrieve AF, Hazard L \& Shrieve DC. Overall and progression-free survival and visual and endocrine outcomes for patients with parasellar lesions treated with intensity-modulated stereotactic radiosurgery. Journal of Neuro-Oncology 201098 221-231. (https://doi.org/10.1007/s11060-010-0174-0)

12 Castinetti F, Nagai M, Dufour H, Kuhn JM, Morange I, Jaquet P, Conte-Devolx B, Regis J \& Brue T. Gamma knife radiosurgery is a successful adjunctive treatment in Cushing's disease. European Journal of Endocrinology 2007156 91-98. (https://doi.org/10.1530/ eje.1.02323)

13 Mehta GU, Ding D, Patibandla MR, Kano H, Sisterson N, Su YH, Krsek M, Nabeel AM, El-Shehaby A, Kareem KA et al. Stereotactic radiosurgery for Cushing disease: results of an international, Multicenter Study. Journal of Clinical Endocrinology and Metabolism 2017102 4284-4291. (https://doi.org/10.1210/ jc.2017-01385)

14 Abu Dabrh AM, Singh Ospina NM, Al Nofal A, Farah WH, Barrionuevo P, Sarigianni M, Mohabbat AB, Benkhadra K, Carranza Leon BG, Gionfriddo MR et al. Predictors of biochemical remission and recurrence after surgical and radiation treatments of Cushing disease: a systematic review and meta-analysis. Endocrine Practice 201622 466-475. (https://doi.org/10.4158/EP15922.RA)

15 Gupta A, Xu Z, Kano H, N, Su YH, Krsek M, Nabeel AM, El-Shehaby A, Karim KA, Martínez-Moreno N et al. Upfront gamma Knife radiosurgery for Cushing's disease and acromegaly: a multicenter, international study. Journal of Neurosurgery 2018 Epub. (https://doi.org/10.3171/2018.3.JNS18110)

16 Castinetti F, Regis J, Dufour H \& Brue T. Role of stereotactic radiosurgery in the management of pituitary adenomas. Nature Reviews: Endocrinology 20106 214-223. (https://doi.org/10.1038/ nrendo.2010.4)

17 Stalla GK, Stalla J, Loeffler JP, von Werder K \& Muller OA. Pharmacological modulation of CRH-stimulated ACTH secretion by ketoconazole. Hormone and Metabolic Research: Supplement Series 1987 $1631-36$.

18 Moore JM, Sala E, Amorin A, Martinez H Jr, Bhowmik AC, Chang SD, Soltys SG, Harsh GR \& Katznelson L. CyberKnife radiosurgery in the multimodal management of patients with Cushing disease. World Neurosurgery 2018112 e425-e430. (https://doi.org/10.1016/j. wneu.2018.01.057)

19 Shepard MJ, Mehta GU, Xu Z, Kano H, Sisterson N, Su YH, Krsek M, Nabeel AM, El-Shehaby A, Kareem KA et al. Technique of wholesellar stereotactic radiosurgery for Cushing disease: results from a multicenter, international cohort study. World Neurosurgery 2018116 e670-e679. (https://doi.org/10.1016/j.wneu.2018.05.067)

20 Castinetti F, Nagai M, Morange I, Dufour H, Caron P, Chanson P, Cortet-Rudelli C, Kuhn JM, Conte-Devolx B, Regis J et al. Long-term results of stereotactic radiosurgery in secretory pituitary adenomas. Journal of Clinical Endocrinology and Metabolism 200994 3400-3407. (https://doi.org/10.1210/jc.2008-2772)

21 Xu Z, Lee Vance M, Schlesinger D \& Sheehan JP. Hypopituitarism after stereotactic radiosurgery for pituitary adenomas. Neurosurgery 201372 630-637; 636-637. (https://doi.org/10.1227/ NEU.0b013e3182846e44)

22 Lee CC, Vance ML, Xu Z, Yen CP, Schlesinger D, Dodson B \& Sheehan J. Stereotactic radiosurgery for acromegaly. Journal of Clinical Endocrinology and Metabolism 201499 1273-1281. (https://doi. org/10.1210/jc.2013-3743)

23 Sheehan JP, Starke RM, Mathieu D, Young B, Sneed PK, Chiang VL, Lee JY, Kano H, Park KJ, Niranjan A et al. Gamma Knife radiosurgery for the management of nonfunctioning pituitary adenomas: a multicenter study. Journal of Neurosurgery 2013119 446-456. (https:// doi.org/10.3171/2013.3.JNS12766)
24 Starke RM, Williams BJ, Jane JA Jr \& Sheehan JP. Gamma Knife surgery for patients with nonfunctioning pituitary macroadenomas: predictors of tumor control, neurological deficits, and hypopituitarism. Journal of Neurosurgery 2012117 129-135. (https:// doi.org/10.3171/2012.4.JNS112250)

25 Kopp C, Theodorou M, Poullos N, Jacob V, Astner ST, Molls M \& Grosu AL. Tumor shrinkage assessed by volumetric MRI in long-term follow-up after fractionated stereotactic radiotherapy of nonfunctioning pituitary adenoma. International Journal of Radiation Oncology, Biology, Physics 201282 1262-1267. (https://doi. org/10.1016/j.ijrobp.2011.02.053)

26 Brummelman P, Sattler MG, Meiners LC, Elderson MF, Dullaart RP, van den Berg G, Koerts J, Tucha O, Wolffenbuttel BH, van den Bergh AC et al. Cognitive performance after postoperative pituitary radiotherapy: a dosimetric study of the hippocampus and the prefrontal cortex. European Journal of Endocrinology 2012166 171-179. (https://doi.org/10.1530/EJE-11-0749)

27 Burman P, Mattsson AF, Johannsson G, Hoybye C, Holmer H, Dahlqvist P, Berinder K, Engstrom BE, Ekman B, Erfurth EM et al. Deaths among adult patients with hypopituitarism: hypocortisolism during acute stress, and de novo malignant brain tumors contribute to an increased mortality. Journal of Clinical Endocrinology and Metabolism 201398 1466-1475. (https://doi.org/10.1210/jc.20124059)

28 Burman P, van Beek AP, Biller BM, Camacho-Hubner C \& Mattsson AF. Radiotherapy, especially at young age, increases the risk for de novo brain tumors in patients treated for pituitary/sellar lesions. Journal of Clinical Endocrinology and Metabolism 2017102 1051-1058. (https://doi.org/10.1210/jc.2016-3402)

29 Ayuk J. Does pituitary radiotherapy increase the risk of stroke and, if so, what preventative actions should be taken? Clinical Endocrinology 201276 328-331. (https://doi.org/10.1111/j.13652265.2011.04300.x)

30 Sattler MG, Vroomen PC, Sluiter WJ, Schers HJ, van den Berg G, Langendijk JA, Wolffenbuttel BH, van den Bergh AC \& van Beek AP. Incidence, causative mechanisms, and anatomic localization of stroke in pituitary adenoma patients treated with postoperative radiation therapy versus surgery alone. International Journal of Radiation Oncology, Biology, Physics 201387 53-59. (https://doi. org/10.1016/j.ijrobp.2013.05.006)

31 Tooze A, Hiles CL \& Sheehan JP. Neurocognitive changes in pituitary adenoma patients after gamma knife radiosurgery: a preliminary study. World Neurosurgery 201278 122-128. (https://doi. org/10.1016/j.wneu.2011.09.010)

32 Feelders RA, Newell-Price J, Pivonello R, Nieman LK, Hofland LJ \& Lacroix A. Advances in the medical treatment of Cushing's syndrome. Lancet: Diabetes and Endocrinology 20197 300-312. (https://doi.org/10.1016/S2213-8587(18)30155-4)

33 Castinetti F, Guignat L, Giraud P, Muller M, Kamenicky P, Drui D, Caron P, Luca F, Donadille B, Vantyghem MC et al. Ketoconazole in Cushing's disease: is it worth a try? Journal of Clinical Endocrinology and Metabolism 201499 1623-1630. (https://doi.org/10.1210/ jc.2013-3628)

34 Daniel E, Aylwin S, Mustafa O, Ball S, Munir A, Boelaert K, Chortis V, Cuthbertson DJ, Daousi C, Rajeev SP et al. Effectiveness of metyrapone in treating Cushing's syndrome: a retrospective multicenter study in 195 patients. Journal of Clinical Endocrinology and Metabolism 2015100 4146-4154. (https://doi.org/10.1210/jc.20152616)

35 Broersen LHA, Jha M, Biermasz NR, Pereira AM \& Dekkers OM. Effectiveness of medical treatment for Cushing's syndrome: a systematic review and meta-analysis. Pituitary 201821 631-641. (https://doi.org/10.1007/s11102-018-0897-z)

36 Sarkis P, Rabilloud M, Lifante JC, Siamand A, Jouanneau E, Gay E, Chaffanjon P, Chabre O \& Raverot G. Bilateral adrenalectomy in Cushing's disease: altered long-term quality of life compared to other 
treatment options. Annales d'Endocrinologie 201980 32-37. (https:// doi.org/10.1016/j.ando.2018.01.002)

37 Assie G, Bahurel H, Coste J, Silvera S, Kujas M, Dugue MA, Karray F, Dousset B, Bertherat J, Legmann P et al. Corticotroph tumor progression after adrenalectomy in Cushing's disease: a reappraisal of Nelson's syndrome. Journal of Clinical Endocrinology and Metabolism 200792 172-179. (https://doi.org/10.1210/jc.2006-1328)

38 Guerin C, Taieb D, Treglia G, Brue T, Lacroix A, Sebag F \& Castinetti F. Bilateral adrenalectomy in the 21st century: when to use it for hypercortisolism? Endocrine-Related Cancer 201623 R131-R142. (https://doi.org/10.1530/ERC-15-0541)

39 Dekkers OM, Biermasz NR, Pereira AM, Roelfsema F, van Aken MO, Voormolen JH \& Romijn JA. Mortality in patients treated for Cushing's disease is increased, compared with patients treated for nonfunctioning pituitary macroadenoma. Journal of Clinical Endocrinology and Metabolism 200792 976-981. (https://doi. org/10.1210/jc.2006-2112)

40 Lindholm J, Juul S, Jorgensen JO, Astrup J, Bjerre P, FeldtRasmussen U, Hagen C, Jorgensen J, Kosteljanetz M, Kristensen L et al. Incidence and late prognosis of Cushing's syndrome: a population-based study. Journal of Clinical Endocrinology and Metabolism 200186 117-123. (https://doi.org/10.1210/ jcem.86.1.7093)

41 Hammer GD, Tyrrell JB, Lamborn KR, Applebury CB, Hannegan ET, Bell S, Rahl R, Lu A \& Wilson CB. Transsphenoidal microsurgery for Cushing's disease: initial outcome and long-term results. Journal of Clinical Endocrinology and Metabolism 200489 6348-6357. (https:// doi.org/10.1210/jc.2003-032180)

42 Clayton RN, Raskauskiene D, Reulen RC \& Jones PW. Mortality and morbidity in Cushing's disease over 50 years in Stoke-on-Trent, UK: audit and meta-analysis of literature. Journal of Clinical Endocrinology and Metabolism 201196 632-642. (https://doi.org/10.1210/jc.20101942)

43 Hassan-Smith ZK, Sherlock M, Reulen RC, Arlt W, Ayuk J, Toogood AA, Cooper MS, Johnson AP \& Stewart PM. Outcome of Cushing's disease following transsphenoidal surgery in a single center over 20 years. Journal of Clinical Endocrinology and Metabolism 201297 1194-1201. (https://doi.org/10.1210/jc.2011-2957)

44 Bolland MJ, Holdaway IM, Berkeley JE, Lim S, Dransfield WJ, Conaglen JV, Croxson MS, Gamble GD, Hunt PJ \& Toomath RJ. Mortality and morbidity in Cushing's syndrome in New Zealand. Clinical Endocrinology 201175 436-442. (https://doi.org/10.1111/ j.1365-2265.2011.04124.x)

45 Ragnarsson O, Olsson DS, Papakokkinou E, Chantzichristos D, Dahlqvist P, Segerstedt E, Olsson T, Petersson M, Berinder K, Bensing $\mathrm{S}$ et al. Overall and disease-specific mortality in patients with Cushing's disease: a Swedish nationwide study. Journal of Clinical Endocrinology and Metabolism 2019 Epub. (https://doi.org/10.1210/ jc.2018-02524)

46 Pivonello R, Isidori AM, De Martino MC, Newell-Price J, Biller BM \& Colao A. Complications of Cushing's syndrome: state of the art. Lancet: Diabetes and Endocrinology 20164 611-629. (https://doi. org/10.1016/S2213-8587(16)00086-3)

47 Dekkers OM, Horvath-Puho E, Jorgensen JO, Cannegieter SC, Ehrenstein V, Vandenbroucke JP, Pereira AM \& Sorensen HT. Multisystem morbidity and mortality in Cushing's syndrome: a cohort study. Journal of Clinical Endocrinology and Metabolism 201398 2277-2284. (https://doi.org/10.1210/jc.2012-3582)

48 Patil CG, Veeravagu A, Prevedello DM, Katznelson L, Vance ML \& Laws ER Jr. Outcomes after repeat transsphenoidal surgery for recurrent Cushing's disease. Neurosurgery 200863 266-270; discussion 270-261. (https://doi.org/10.1227/01. NEU.0000313117.35824.9F)

49 Howlett TA, Plowman PN, Wass JA, Rees LH, Jones AE \& Besser GM. Megavoltage pituitary irradiation in the management of Cushing's disease and Nelson's syndrome: long-term follow-up. Clinical Endocrinology 198931 309-323. (https://doi. org/10.1111/j.1365-2265.1989.tb01255.x)

50 Minniti G, Osti M, Jaffrain-Rea ML, Esposito V, Cantore G \& Maurizi Enrici R. Long-term follow-up results of postoperative radiation therapy for Cushing's disease. Journal of Neuro-Oncology $2007 \mathbf{8 4}$ 79-84. (https://doi.org/10.1007/s11060-007-9344-0)

51 Murayama M, Yasuda K, Minamori Y, Mercado-Asis LB, Yamakita N \& Miura K. Long term follow-up of Cushing's disease treated with reserpine and pituitary irradiation. Journal of Clinical Endocrinology and Metabolism 199275 935-942. (https://doi.org/10.1210/ jcem.75.3.1517389)

52 Tsang RW, Brierley JD, Panzarella T, Gospodarowicz MK, Sutcliffe SB \& Simpson WJ. Role of radiation therapy in clinical hormonallyactive pituitary adenomas. Radiotherapy and Oncology 199641 45-53. (https://doi.org/10.1016/S0167-8140(96)91807-1)

53 Estrada J, Boronat M, Mielgo M, Magallon R, Millan I, Diez S, Lucas T \& Barcelo B. The long-term outcome of pituitary irradiation after unsuccessful transsphenoidal surgery in Cushing's disease. New England Journal of Medicine 1997336 172-177. (https://doi. org/10.1056/NEJM199701163360303)

54 Littley MD, Shalet SM, Beardwell CG, Ahmed SR \& Sutton ML. Long-term follow-up of low-dose external pituitary irradiation for Cushing's disease. Clinical Endocrinology 199033 445-455. (https:// doi.org/10.1111/j.1365-2265.1990.tb03883.x)

55 Sonino N, Zielezny M, Fava GA, Fallo F \& Boscaro M. Risk factors and long-term outcome in pituitary-dependent Cushing's disease. Journal of Clinical Endocrinology and Metabolism 199681 2647-2652. (https:// doi.org/10.1210/jcem.81.7.8675592)

56 Devin JK, Allen GS, Cmelak AJ, Duggan DM \& Blevins LS. The efficacy of linear accelerator radiosurgery in the management of patients with Cushing's disease. Stereotactic and Functional Neurosurgery 200482 254-262. (https://doi.org/10.1159/000083476)

57 Colin P, Jovenin N, Delemer B, Caron J, Grulet H, Hecart AC, Lukas C, Bazin A, Bernard MH, Scherpereel B et al. Treatment of pituitary adenomas by fractionated stereotactic radiotherapy: a prospective study of 110 patients. International Journal of Radiation Oncology, Biology, Physics 200562 333-341. (https://doi. org/10.1016/j.ijrobp.2004.09.058)

58 Jagannathan J, Sheehan JP, Pouratian N, Laws ER, Steiner L \& Vance ML. Gamma Knife surgery for Cushing's disease. Journal of Neurosurgery 2007106 980-987. (https://doi.org/10.3171/ jns.2007.106.6.980)

59 Sheehan JP, Xu Z, Salvetti DJ, Schmitt PJ \& Vance ML. Results of gamma knife surgery for Cushing's disease. Journal of Neurosurgery 2013119 1486-1492. (https://doi. org/10.3171/2013.7.JNS13217)

60 Wattson DA, Tanguturi SK, Spiegel DY, Niemierko A, Biller BM, Nachtigall LB, Bussiere MR, Swearingen B, Chapman PH, Loeffler JS et al. Outcomes of proton therapy for patients with functional pituitary adenomas. International Journal of Radiation Oncology, Biology, Physics 201490 532-539. (https://doi.org/10.1016/j. ijrobp.2014.06.068)

61 Pappachan JM, Raskauskiene D, Kutty VR \& Clayton RN. Excess mortality associated with hypopituitarism in adults: a meta-analysis of observational studies. Journal of Clinical Endocrinology and Metabolism 2015100 1405-1411. (https://doi.org/10.1210/ jc.2014-3787)

62 Sherlock M, Ayuk J, Tomlinson JW, Toogood AA, Aragon-Alonso A, Sheppard MC, Bates AS \& Stewart PM. Mortality in patients with pituitary disease. Endocrine Reviews 201031 301-342. (https://doi. org/10.1210/er.2009-0033)

63 Filipsson H, Monson JP, Koltowska-Haggstrom M, Mattsson A \& Johannsson G. The impact of glucocorticoid replacement regimens on metabolic outcome and comorbidity in hypopituitary patients. Journal of Clinical Endocrinology and Metabolism 200691 3954-3961. (https://doi.org/10.1210/jc.2006-0524) 
64 Ragnarsson O, Nystrom HF \& Johannsson G. Glucocorticoid replacement therapy is independently associated with reduced bone mineral density in women with hypopituitarism. Clinical Endocrinology 201276 246-252. (https://doi.org/10.1111/j.1365-2265.2011.04174.x)

65 Ragnarsson O, Mattsson AF, Monson JP, Filipsson Nystrom H, Akerblad AC, Koltowska-Haggstrom M \& Johannsson G. The relationship between glucocorticoid replacement and quality of life in 2737 hypopituitary patients. European Journal of Endocrinology 2014171 571-579. (https://doi.org/10.1530/EJE-14-0397)

66 Hahner S, Loeffler M, Fassnacht M, Weismann D, Koschker AC, Quinkler M, Decker O, Arlt W \& Allolio B. Impaired subjective health status in 256 patients with adrenal insufficiency on standard therapy based on cross-sectional analysis. Journal of Clinical Endocrinology and Metabolism 200792 3912-3922. (https://doi.org/10.1210/jc.2007-0685)

67 O'Reilly MW, Reulen RC, Gupta S, Thompson CA, Dineen R, Goulden EL, Bugg G, Pearce H, Toogood AA, Gittoes NJ et al. ACTH and gonadotropin deficiencies predict mortality in patients treated for nonfunctioning pituitary adenoma: long-term follow-up of 519 patients in two large European centres. Clinical Endocrinology $2016 \mathbf{8 5}$ 748-756. (https://doi.org/10.1111/cen.13141)

68 Hammarstrand C, Ragnarsson O, Hallen T, Andersson E, Skoglund T, Nilsson AG, Johannsson G \& Olsson DS. Higher glucocorticoid replacement doses are associated with increased mortality in patients with pituitary adenoma. European Journal of Endocrinology $2017 \mathbf{1 7 7}$ 251-256. (https://doi.org/10.1530/EJE-17-0340)

69 Tomlinson JW, Holden N, Hills RK, Wheatley K, Clayton RN, Bates AS, Sheppard MC \& Stewart PM. Association between premature mortality and hypopituitarism. West Midlands Prospective Hypopituitary Study Group. Lancet 2001357 425-431. (https://doi. org/10.1016/S0140-6736(00)04006-X)

70 Klose M, Marina D, Hartoft-Nielsen ML, Klefter O, Gavan V, Hilsted L, Rasmussen AK \& Feldt-Rasmussen U. Central hypothyroidism and its replacement have a significant influence on cardiovascular risk factors in adult hypopituitary patients. Journal of Clinical Endocrinology and Metabolism 201398 3802-3810. (https:// doi.org/10.1210/jc.2013-1610)

71 Giagulli VA, Castellana M, Perrone R, Guastamacchia E, Iacoviello M \& Triggiani V. GH supplementation effects on cardiovascular risk in GH deficient adult patients: a systematic review and meta-analysis. Endocrine, Metabolic and Immune Disorders Drug Targets 201717 285-296. (https://doi.org/10.2174/1871530317666170919121729)

72 Tjornstrand A, Gunnarsson K, Evert M, Holmberg E, Ragnarsson O, Rosen $\mathrm{T} \&$ Filipsson Nystrom $\mathrm{H}$. The incidence rate of pituitary adenomas in western Sweden for the period 2001-2011. European Journal of Endocrinology 2014171 519-526. (https://doi.org/10.1530/ EJE-14-0144)

73 Cifarelli CP, Schlesinger DJ \& Sheehan JP. Cranial nerve dysfunction following gamma Knife surgery for pituitary adenomas: longterm incidence and risk factors. Journal of Neurosurgery 2012116 1304-1310. (https://doi.org/10.3171/2012.2.JNS111630)

74 Erfurth EM, Bulow B, Mikoczy Z, Svahn-Tapper G \& Hagmar L. Is there an increase in second brain tumours after surgery and irradiation for a pituitary tumour? Clinical Endocrinology 200155 613-616. (https://doi.org/10.1046/j.1365-2265.2001.01385.x)

75 Yamanaka R, Abe E, Sato T, Hayano A \& Takashima Y. Secondary intracranial tumors following radiotherapy for pituitary adenomas: a systematic review. Cancers 20179 E103. (https://doi.org/10.3390/ cancers9080103)

76 Norberg L, Johansson R \& Rasmuson T. Intracranial tumours after external fractionated radiotherapy for pituitary adenomas in northern Sweden. Acta Oncologica 201049 1276-1282. (https://doi. org/10.3109/02841861003782025)

77 Brada M, Ford D, Ashley S, Bliss JM, Crowley S, Mason M, Rajan B $\&$ Traish D. Risk of second brain tumour after conservative surgery and radiotherapy for pituitary adenoma. BMJ $1992 \mathbf{3 0 4} 1343-1346$. (https://doi.org/10.1136/bmj.304.6838.1343)

78 Minniti G, Traish D, Ashley S, Gonsalves A \& Brada M. Risk of second brain tumor after conservative surgery and radiotherapy for pituitary adenoma: update after an additional 10 years. Journal of Clinical Endocrinology and Metabolism 200590 800-804. (https://doi. org/10.1210/jc.2004-1152)

79 Sattler MG, van Beek AP, Wolffenbuttel BH, van den Berg G, Sluiter WJ, Langendijk JA \& van den Bergh AC. The incidence of second tumours and mortality in pituitary adenoma patients treated with postoperative radiotherapy versus surgery alone. Radiotherapy and Oncology 2012104 125-130. (https://doi.org/10.1016/j. radonc.2012.04.024)

80 Brada M, Burchell L, Ashley S \& Traish D. The incidence of cerebrovascular accidents in patients with pituitary adenoma. International Journal of Radiation Oncology, Biology, Physics 199945 693-698. (https://doi.org/10.1016/S0360-3016(99)00159-5)

81 Nilsson B, Gustavasson-Kadaka E, Bengtsson BA \& Jonsson B. Pituitary adenomas in Sweden between 1958 and 1991: incidence, survival, and mortality. Journal of Clinical Endocrinology and Metabolism 200085 1420-1425. (https://doi.org/10.1210/ jcem.85.4.6498)

82 van Varsseveld NC, van Bunderen CC, Ubachs DH, Franken AA Koppeschaar HP, van der Lely AJ \& Drent ML. Cerebrovascular events, secondary intracranial tumors, and mortality after radiotherapy for nonfunctioning pituitary adenomas: a subanalysis from the Dutch National Registry of Growth Hormone Treatment in Adults. Journal of Clinical Endocrinology and Metabolism $2015 \mathbf{1 0 0}$ 1104-1112. (https://doi.org/10.1210/jc.2014-3697)

83 van Westrhenen A, Muskens IS, Verhoeff JJC, Smith TRS \& Broekman MLD. Ischemic stroke after radiation therapy for pituitary adenomas: a systematic review. Journal of Neuro-Oncology $2017 \mathbf{1 3 5}$ 1-11. (https://doi.org/10.1007/s11060-017-2530-9)

84 Noad R, Narayanan KR, Howlett T, Lincoln NB \& Page RC. Evaluation of the effect of radiotherapy for pituitary tumours on cognitive function and quality of life. Clinical Oncology 200416 233-237. (https://doi.org/10.1016/j.clon.2004.01.012)

85 Lecumberri B, Estrada J, Garcia-Uria J, Millan I, Pallardo LF, Caballero L \& Lucas T. Neurocognitive long-term impact of two-field conventional radiotherapy in adult patients with operated pituitary adenomas. Pituitary 201518 782-795. (https://doi.org/10.1007/ s11102-015-0653-6)

86 Brummelman P, Sattler MG, Meiners LC, van den Berg G, van der Klauw MM, Elderson MF, Dullaart RP, Koerts J, Werumeus Buning J, Tucha $\mathrm{O}$ et al. Cognition and brain abnormalities on MRI in pituitary patients. European Journal of Radiology 201584 295-300. (https://doi. org/10.1016/j.ejrad.2014.11.033)

87 Brummelman P, Elderson MF, Dullaart RP, van den Bergh AC, Timmer CA, van den Berg G, Koerts J, Tucha O, Wolffenbuttel BH $\&$ van Beek AP. Cognitive functioning in patients treated for nonfunctioning pituitary macroadenoma and the effects of pituitary radiotherapy. Clinical Endocrinology 201174 481-487. (https://doi. org/10.1111/j.1365-2265.2010.03947.x)

88 Tooze A \& Sheehan JP. Neurocognitive changes in pituitary adenoma patients after gamma Knife radiosurgery. Journal of Neurosurgery 2018 129 55-62. (https://doi.org/10.3171/2018.7.GKS181595)

Received 12 February 2019

Revised version received 23 March 2019

Accepted 3 April 2019 